\title{
PENGARUH PENAMBAHAN TEPUNG BUAH MANGROV PEDADA (Sonneratia caseolaris) PADA MUTU DODOL KETAN
}

\section{THE UTILIZATION OF MANGROVE PEDADA FRUIT (Sonneratia caseolaris) AS THE RAW MATERIAL FOR DODOL}

\author{
Nurfadilah $^{* 1}$ \\ ${ }^{1}$ Program Studi Program Studi Teknologi Pengolahan Hasil Laut, Politeknik Palu \\ Jln. Sinarkemuning 1 No. 1A Palu 94118 Sulawesi Tengah Indonesia
}

\begin{abstract}
ABSTRAK
Mangrove merupakan tumbuhan yang hidup dipinggir pantai dengan bermacam-macam jenis mangrove, namun mangrove yang digunakan dalam penelitian yaitu jenis pedada, masyarakat Eropa mengenalnya dengan sebutan Sonneratiacaseolaris. Ekosistem mangrove memiliki manfaat ekonomis yaitu hasil kayu dan bukan kayu misalnya budidaya air payau, tambak udang, pariwisata dan lainnya. Manfaat ekologis adalah berupa perlindungan bagi ekosis tem daratan dan lautan, yaitu dapat menjadi penahan abrasi atau erosi gelombang atau angin kencang.Mangrove mempunyai nilai ekonomis penting karena memiliki kan dungan karbohidrat yang tinggi. Penelitian ini bertujuan untuk mengetahui tingkat subtitusi tepung ketan dan tepung mangrove pedada yang menghasilkan dodol dengan mutu organoleptik yang tinggi. Penelitian ini menggunakan Rancangan Acak Kelompok (RAK) dengan 5 perlakuan.Dari hasil keseluruhan ujiorganoleptik diatas yang dinilai oleh penelis dari tingkat kesukaan warna, aroma, rasa, tekstur, dan kesukaan keseluruhan menunjukan bahwa penelis lebih menyukai tingkat subsitusi $10 \%$ dengan menggunakan 20 gram tepung mangrove dan 180 gram tepung ketan.
\end{abstract}

Katakunci: pemanfaatan buah mangrove, bahan baku dodol

\begin{abstract}
Mangroves are plants that live on the shores of the coast with various types of mangroves, but the mangroves used in the study are pedada, European communities know him with designation Sonneratia caseolaris. Mangrove ecosystems have benefits economical that is results wood and notwoodfor example brackish water cultivation, ponds shrimp, tour a and others. Benefits ecological is in the form of protection for the ecosystem mainlandand the ocean, that is could to be anchoring abrasion or erosion wave or wind tight. Mangroves have value economical important because have rightdungan high arbohydrates. Research this aiming for knowing level substitution flour sticky rice and which produces mangrove mangrove flour dodol with organoleptic high quality. This study used a Randomized Block Design (RBD) with 5 treatments. From the results whole test organoleptic above assessed by penelis from level fondness color, aroma, taste, texture, and fondness whole showing that penelis more like level $10 \%$ substitution with use 20 grams of mangrove flour and 180 grams of flour sticky rice.
\end{abstract}

Keywords: Utilization of Mangroves, Dodol Raw Materials

\section{Pendahuluan}

Indonesia sebagai negara kepulauan terbesar di dunia memiliki 17,508 pulau dengan garis pantai sepanjang $81,000 \mathrm{~km}$ dan memiliki potensi sumberdaya pesisir dan lautan yang sangat besar (Bengen, 2002). Sumberdaya alam yang terdapat di wilayah pesisir dan lautan terdiri

\footnotetext{
${ }^{*}$ Penulis Korespondensi.

E-mail: nurfadillah.mh@gmail.com.

HP : 085241327039
}

dari sumberdaya alam yang dapat diperbaharui (renewable resources) seperti perikanan, hutan mangrove dan terumbu karang maupun sumberdaya yang tidak dapat diperbaharui (nonrenewable resources) seperti minyak bumi dan gas alam. Ekosistem mangrove memiliki manfaat ekonomis yaitu hasil kayu dan bukan kayu misalnya budidaya air payau, tambak udang, pariwisata dan lainnya.Manfaat ekologis adalah berupa perlindungan bagi ekosistem daratan dan lautan, yaitu dapat menjadi penahan abrasi atau 
erosi gelombang atau angin kencang. Produk hutan mangrove yang sering di manfaatkan manusia adalah kayu yang digunakan sebagai bahan bakar, bahan membuat perahu, tannin untuk pengawet jaring, lem bahan pewarna kain dan lain-lain (Dahuri., et all 2001).

Pangan merupakan kebutuhan dasar manusia yang hakiki dan pemenuhan pangan harus dilaksanakan secara adil dan merataberdasarkan kemandirian dan tidak bertentangan dengan keyakinan masyarakat seperti yang dimanfaatkan oleh UU No. 7 tahun 1996 tentang pangan.Belum banyakpengetahuan tentang potensi dan manfaat mangrove sebagai sumber pangan. Penelitian yang dilakukan Hudaya (2008)pada masyarakat kampung rayori, memberikan informasi bahwa masyarakat telah memanfaatkan buah mangrove untuk di konsumsi sebagai makanan terutama jenis buah mangrove pedada.

Dalam menjalankan usaha bisnis, pelaku bisnis memerlukan strategi yang bagus sebagai alat yang sangat penting untuk mencapai tujuannya, strategi diperlukan untuk mengelolah berbagai usaha, sebagimana diketahui bahwa kondisi dunia usaha penuh diwarnai dengan adanya perubahan dari waktu ke waktu dan sifatnya dinamis.

Menurut Abdul majid (2008), strategi pemasaran yang berhasil umumnya ditentukan dari satu atau beberapa variabel marketing mix nya. Jadi wirausahawan dapat mengembangkan strategi produk, harga, distribusi dan promosi, atau mengkombinasikan variabel-variabel tersebut kedalam suatu rencana strategi yang menyeluruh".

Masyarakat Indonesia belum memahami betul apa kegunaan dan manfaat dari tanaman dan buah mangrove, masyarakat hanya dapat memahami bahwa ekosistem mangrove hanyalah tanaman yang hidup dipinggir pantai, buah dari tanaman mangrove hanya dijadikan sebagai bahan mainan, sehingga penulis meneliti buah dari tanaman mangrove agar masyarakat dapat memahami dan memanfaatkan buah dari tanaman mangrove.

\section{Perumusan Masalah}

1. Berapa persen subsitusi tepung ketan dengan tepung mangrove pedada yang menghasilkan dodol dengan mutu organoleptik yang baik.

2. Adakah pengaruh strategi pemasaran (Strategi produk, dan strategi promosi) dengan pendekatan lingkungan eksternal terhadap volume penjualan produk dodol buah mangrove.

\section{Tujuan dan Kegunaan}

Penelitian ini bertujuan untuk mengetahui tingkat subsitusi tepung ketan dan tepung mangrove pedada yang menghasilkan dodol dengan mutu organoleptik yang baik dan untuk mengetahui metode pemasaran produk dodol mangrove pedada.

Kegunaan dari penelitian ini adalah untuk memberikan informasi kepada konsumen yang memiliki kepentingan mengenai dodol buah mangrove, dapat membantu dan meningkatkan strategi pemasaran, sehingga dapat lebih berkembang lebih baik dan dapat membantu membangun jiwa kewirausahaan khususnya dikalangan mahasiswa perikanan.

\section{Metode Penelitian}

\section{Alat dan Bahan}

Alat yang digunakan dalam penelitian ini adalah : Kompor, wajan, sendok wajan, timbangan, baskom, gelas ukur, piring, pisau, dan saringan kelapa. Adapun bahan yang digunakan meliputi :Tepung Buah Magrove, tepung ketan, gula merah, dan santan kelapa.

\section{Pelaksanaan Penelitian Rancangan Penelitian}

Rancangan penelitian yang digunakan adalah Rancangan AcakKelompok (RAK) dengan perlakuan tingkat subtitusi tepung ketan dengan tepung mangrove pedada yang terdiri dari lima level masing-masing 10\%, 20\%, 30\%, dan $40 \%$, dan $50 \%$. Adapun formula dodol disajikan pada Tabel 1.

Tabel 1. Formula bahan yang digunakan

\begin{tabular}{llllll|}
\hline \multirow{2}{*}{ Bahan } & \multicolumn{5}{c|}{ Formula (\%) } \\
\cline { 2 - 6 } & \multicolumn{10}{c}{$\mathbf{1 0}$} & $\mathbf{2 0} \%$ & $\mathbf{3 0 \%}$ & $\mathbf{4 0} \%$ & $\mathbf{5 0 \%}$ \\
\hline Tepung Mangrove Pedada & $20 \mathrm{~g}$ & $40 \mathrm{~g}$ & $60 \mathrm{~g}$ & $80 \mathrm{~g}$ & $100 \mathrm{~g}$ \\
Tepung Ketan & $180 \mathrm{~g}$ & $160 \mathrm{~g}$ & $140 \mathrm{~g}$ & $120 \mathrm{~g}$ & $100 \mathrm{~g}$ \\
Santan Kelapa & $400 \mathrm{~mL}$ & $400 \mathrm{~mL}$ & $400 \mathrm{~mL}$ & $400 \mathrm{~mL}$ & $400 \mathrm{~mL}$ \\
Gula Merah & $200 \mathrm{~g}$ & $200 \mathrm{~g}$ & $200 \mathrm{~g}$ & $200 \mathrm{~g}$ & $200 \mathrm{~g}$ \\
\hline
\end{tabular}




\section{Prosedur Penelitian}

\section{Prosedur Pengolahann Tepung Mangrove Pedada}

Penggunaan mangrove pedada (Sonneratia caseolaris) pada pembuatan dodol dalam penelitian ini adalah dengan bentuk tepung yang di sebut dengan tepung mangrove pedada, adapun proses pengolahan tepung mangrove pedada yaitu : Kupas kulit buah mangrove pedada, keluarkan daging buah mangrove pedada, kemudian cuci hingga bersih dan selanjutnya keringkan sampai benar-benar kering, giling daging buah mangrove pedada hasil penjemuran menggunakan blender, kemudian ayak hasil penggilingan hingga halus dan menjadi tepung.

\section{Prosedur Pengolahan Dodol Mangrove Pedada}

Masak gula merah hingga menjadi cair, kemudian masak santan hingga menghampiri menjadi minyak (campur tepung mangrove, tepung ketan, dan gula merah) yang sudah dicairkan kedalam santan yang masak, pengadukan bahan yang sudah dicampurkan menjadi homogen secara terus menerus sampai semua kalis.

\section{Hasil dan Pembahasan}

\section{Nilai Organoleptik Dodol Buah Mangrove Pedada}

\section{Warna Dodol Buah Mangrove Pedada}

Warna merupakan parameter pertama yang menentukan penerimaan konsumen untuk penilaian secara subyektif dengan penglihatan.Penentuan mutu bahan pangan pada umumnya sangat tergantung pada beberapa faktor seperti cita rasa, warna, tekstur, aroma dan nilai gizi, juga sifat mikrobiologis dari bahan pangan tersebut. Sebelum faktor lain dipertimbangkan secara visual, faktor warna tampil terlebih dahulu dan kadang-kadang sangat menentukan dalam penilaian suatu bahan pangan (Winarno, 2002).

Warna makanan memiliki peranan utama dalam penampilan makanan, meskipun makanan tersebut terlihat lezat. Bila penampilan tidak menarik, maka saat disajikan akan mengakibatkan selera orang yang ingin mengkonsumsinya akan hilang (Soekarto, 2002).

Data hasil pengamatan organoleptik warna dodol buah mangrove pedada. Rataan nilai organoleptik warna dodol buah mangrove pedada tertara pada Tabel 2.

\begin{tabular}{ccc}
\hline Subsitusi (\%) & Skor & Nilai Bnj 5\% \\
10 & 7,25 & \\
20 & 7,1 & \\
30 & 7,5 & 0,91 \\
40 & 5,5 & \\
50 & 6,05 & \\
\hline
\end{tabular}

Rataan pengamatan organoleptik warna dodol buah mangrove pedada dengan jumlah tepung buah mangrove pedada dan jumlah tepung beras (Rosebrand) yang bervariasi untuk lebih jelasnya juga disajikan pada Gambar 1.

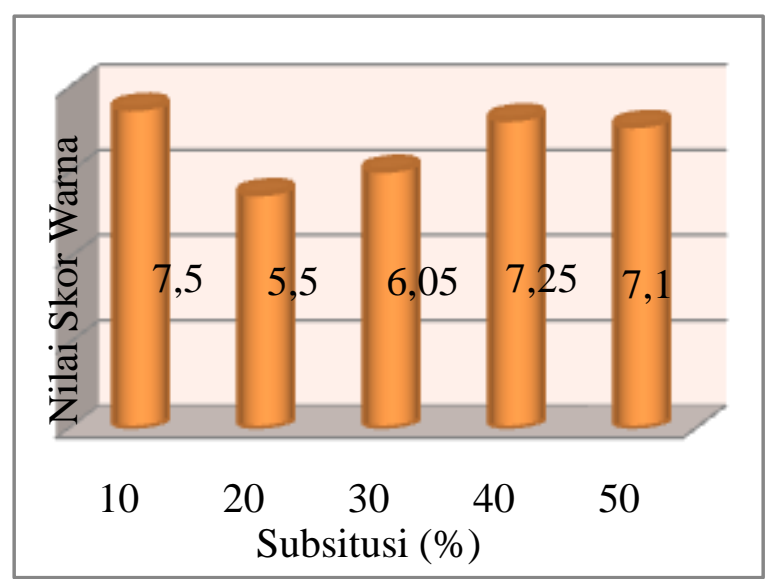

Gambar 1. Histogram warna dodol tepung buah mangrove pedada dengan menggunakan tepung buah mangrove dan tepung ketan yang berjumlah bervariasi.

Gambar 1 diatas menunjukan bahwa nilai organoleptik warna dodol tepung buah mangrove berkisar 5,5 (netral) sampai 7,5 (agak suka). Nilai organoleptik warna tertinggi dan lebih baik yang diberikan panelis terdapat pada pemberian tepung mangrove sebanyak 20 gram dan tepung ketan sebanyak 180 gram (10\%) dibandingkan kandungan tepung mangrove pedada 40 gram dengan tepungketan 160 gram(20\%), tepung mangrove 60 gram dengan tepung ketan 140 gram $(30 \%)$, tepung mangrove 80 gram dengan tepung ketan 120 gram (40\%), dan tepung mangrove 100 gram dengan tepung ketan 100 gram $(50 \%)$.

Hasil analisis ragam menunjukan bahwa jumlah variasi tepung mangrove dan tepung ketan tidak ada pengaruh perlakuan terhadap warna dodol tepung buah mangrove pedada.

Berdasarkan uji Beda Nyata Jujur (BNJ), menunjukan bahwa warna yang diberikan penulis terhadap dodol tepung buah mangrove pedada 20 gram dan tepung ketan 180 gram (10\%) tidak ada pengaruh perlakuan dengan jumlah tepung buah mangrove pedada 40 gram (20\%), 60 gram 
Jurnal Pengolahan Pangan 4 (1) 26-32

(30\%), 80 gram (40\%), dan 100 gram (50\%) dan tepung ketan 160 gram (20\%), 140 gram (30\%), 120 gram (40\%), dan 100 gram (50\%).

\section{Aroma/Bau Dodol Tepung Buah Mangrove}

Indera pencium digunakan untuk menilai bau atau aroma suatu produk pangan.Aroma adalah rasa dan bau yang sangat subyektif serta sulit diukur, karena setiap orang mempunyai sensitifitas dan kesukaan yang berbeda.Meskipun mereka dapat mendeteksi, tetapi setiap individu memiliki kesukaan yang berlainan (Meilgaard $e t$ al. 2000). Dalam industri pangan, uji bau sangat penting karena dapat dengan cepat memberikan hasil penilaian penerimaan konsumen terhadap produksi yang dihasilkan (Soekarto, 2002).

Timbulnya aroma makanan disebabkan oleh terbentuknya senyawa yang mudah menguap.Aroma yang dikeluarkan setiap makanan berbeda-beda. Selain itu, cara memasak yang berbeda akan menimbulkan aroma yang berbeda pula. Molekul gas pada udara yang dihirup tersebut merangsang dan menyentuh selsel peka bau dalam rongga hidung. Bau tersebut akan terasa apabila gas bergerak melewati ujungujung solfaktori (Moehyi 1992).

Data hasil pengamatan organoleptik aroma dodol buah mangrove pedada. Rataan nilai organoleptik aroma dodol buah mangrove pedada tertara pada Tabel 3.

\begin{tabular}{ccc}
\hline Subsitusi (\%) & Skor & NilaiBnj 5\% \\
10 & 3,72 & \\
20 & 4,24 & \\
30 & 3,84 & 0,95 \\
40 & 4 & \\
50 & 4 & \\
\hline
\end{tabular}

Rataan pengamatan organoleptik aroma dodol buah mangrove pedada dengan jumlah tepung buah mangrove pedada dan jumlah tepung beras (Rosebrand) yang bervariasi untuk lebih jelasnya juga disajikan pada Gambar 2.

Gambar 2 diatas menunjukan bahwa nilai organoleptik aroma dodol buah mangrove berkisar 4 (agaksuka) sampai 4,32 (suka). Nilai organoleptik aroma tertinggi dan lebih baik yang diberikan penelis terdapat pada pemberian tepung mangrove sebanyak 20 gram dan tepung ketan sebanyak 180 gram (10\%) dibandingkan dengan kandungan tepung mangrove pedada 40 gram dan tepung ketan 160 gram (20\%), tepung mangrove 60 gram, tepung ketan 140 gram (30\%), tepung mangrove 80 gram, tepung ketan 120 gram (40\%), tepung mangrove 100 gram, tepung ketan $100 \operatorname{gram}(50 \%)$.
e-ISSN : 2621-6973

p-ISSN : 2527-5631

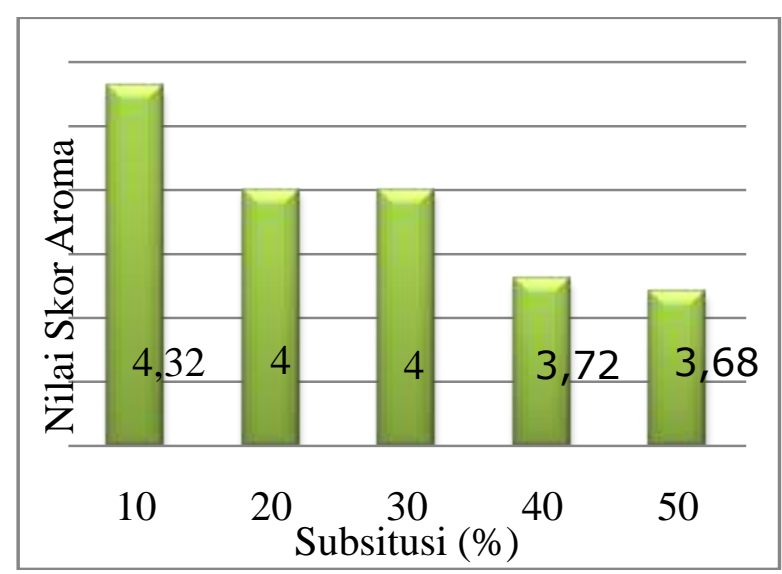

Gambar 2. Histogram aroma dodol tepung buah mangrove pedada dengan menggunakan tepung buah mangrove dan tepung ketan yang berjumlah bervariasi.

Hasil analisis ragam menunjukan bahwa jumlah variasi tepung mangrove dan tepung ketan berbeda nyata terhadap aroma dodol tepung buah mangrove pedada.

Berdasarkan uji Beda Nyata Jujur (BNJ), menunjukan bahwa aroma yang diberikan penelis terhadap dodol tepung buah mangrove pedada 20 gram dan tepung ketan 180 gram (10\%) tidak ada pengaruh perlakuan dengan jumlah tepung buah mangrove pedada 40 gram (20\%), 60 gram (30\%), 80 gram (40\%), dan 100 gram $(50 \%)$ dan tepung ketan 160 gram (20\%), 140 gram (30\%), 120 gram (40\%), dan 100 gram (50\%).

\section{Rasa Dodol Buah Mangrove Pedada}

Rasa makanan merupakan faktor kedua yang mempengaruhi citarasa makanan setelah penampilan makanan itu sendiri (Moehyi 1992). Rasa (flavour) makanan yang kita kenal sehari hari sebenarnya bukan satu tanggapan, melainkan campuran dari tanggapan cicip, bau dan trigeminal yang dirumuskan oleh kesan lain seperti penglihatan, sentuhan dan pendengaran. Rasa merupakan tanggapan atas adanya rangsangan kimiawi yang sampai di indera pengecap lidah, khususnya jenis rasa dasar yaitu manis, asin, asam, dan pahit. Pada konsumsi tinggi indera pengecap akan mudah mengenal rasa-rasa dasar tersebut. Beberapa komponen yang berperan dalam penentuan rasa makanan adalah aroma makanan, bumbu masakan dan bahan makanan, keempukan atau kekenyalan makanan, kerenyahan makanan, tingkat kematangan dan temperatur makanan (Meilgaard et al. 2000).

Data hasil pengamatan organoleptik rasa dodol buah mangrove pedada. Rataan nilai 
organoleptik rasa dodol buah mangrove pedada tertara pada Tabel 4.

\begin{tabular}{ccc}
\hline Subsitusi (\%) & Skor & NilaiBnj 5\% \\
10 & 4 & \\
20 & 3,72 & \\
30 & 4,6 & 0,48 \\
40 & 3,36 & \\
50 & 3.96 & \\
\hline
\end{tabular}

Rataan pengamatan organoleptik rasa dodol buah mangrove pedada dengan jumlah tepung buah mangrove pedada dan jumlah tepung beras (Rosebrand) yang bervariasi untuk lebih jelasnya juga disajikan pada Gambar 3.

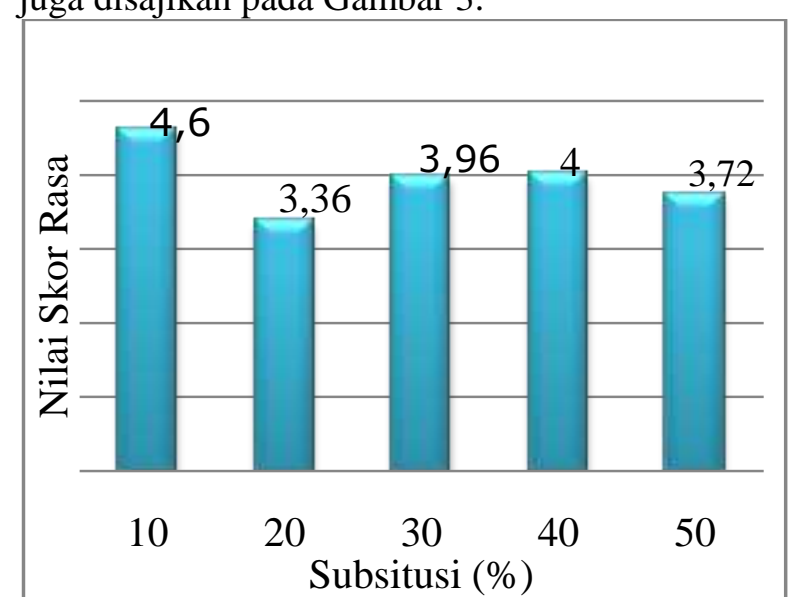

Gambar 3. Histogram rasa dodol tepung buah mangrove pedada dengan menggunakan tepung buah mangrove dan tepung ketan yang berjumlah bervariasi.

Gambar 3 diatas menunjukan bahwa nilai organoleptik rasa dodol buah mangrove berkisar 4 (agak suka) sampai 4,6 (sangat suka). Nilai organoleptik rasa tertinggi dan lebih baik yang diberikan penelis terdapat pada pemberian tepung mangrove sebanyak 20 gram dan tepung ketan sebanyak 180 gram (10\%) dibandingkan dengan kandungan tepung mangrove pedada 40 gram dan tepung ketan 160 gram (20), tepung mangrove 60 gram, tepung ketan 140 gram (30\%), tepung mangrove 80 gram, tepung ketan 120 gram (40\%), tepung mangrove 100 gram, tepung ketan 100 gram (50\%).

Hasil analisis ragam menunjukan bahwa jumlah variasi tepung mangrove dan tepung ketan memberikan pengaruh sangat nyata terhadap rasa dodol buah mangrove pedada.

Berdasarkan uji Beda Nyata Jujur (BNJ), menunjukan bahwa rasa yang diberikan penelis terhadap dodol tepung buah mangrove pedada 20 gram dan tepung ketan 180 gram (10\%) tidak ada pengaruh perlakuan dengan jumlah tepung buah mangrove pedada 40 gram (20\%), 60 gram $(30 \%), 80$ gram $(40 \%)$, dan 100 gram $(50 \%)$ dan tepung ketan 160 gram (20\%), 140 gram (30\%), 120 gram (40\%), dan 200 gram (50\%).

\section{Tekstur Dodol Buah Mangrove Pedada}

Menurut Hardiman (1991), Tekstur adalah salah satu sifat bahan atau produk yang dapat dirasakan melalui sentuhan kulit ataupun pencicipan. Beberapa sifat tekstur dapat juga diperkirakan dengan menggunakan sebelah mata (berkedip) seperti kehalusan atau kekerasan dari permukaan bahan atau kekentalan cairan. Sedangkan dengan suara/bunyi dapat diperkirakan tekstur dari kerupuk (crisp food). Ada dua jenis dasar tekstur yaitu,

1. Tekstur rill adalah tekstur yang memang nyata dan dapat dirasakan dengan sentuhan.

2. Tekstur visual adalah tekstur yang hanya terlihat dengan mata.

Data hasil pengamatan organoleptiktekstur dodol buah mangrove pedada. Rataan nilai organoleptik tekstur dodol buah mangrove pedada tertara pada Tabel 5 .

\begin{tabular}{ccc}
\hline Subsitusi (\%) & Skor & Nilai Bnj 5\% \\
10 & 3,2 & \\
20 & 3,16 & \\
30 & 4,56 & 0,84 \\
40 & 3,84 & \\
50 & 4,44 & \\
\hline
\end{tabular}

Rataan pengamatan organoleptik tekstur dodol buah mangrove pedada dengan jumlah tepung buah mangrove pedada dan jumlah tepung beras (Rosebrand) yang bervariasi untuk lebih jelasnya juga disajikan pada Gambar 4.

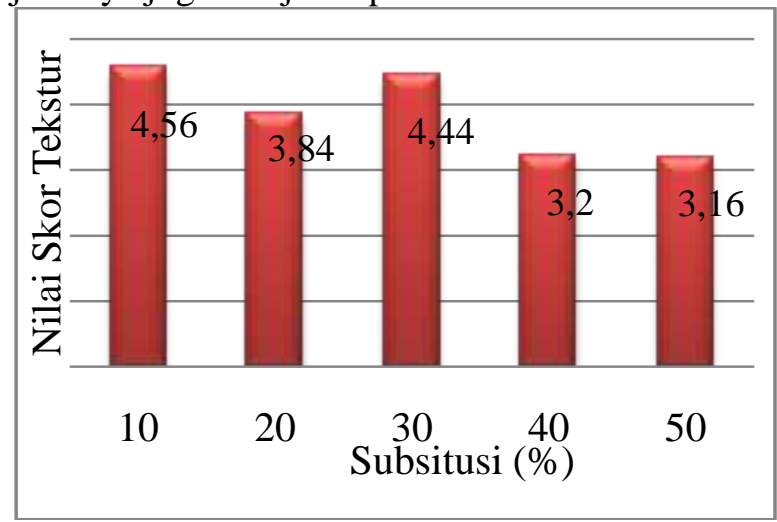

Gambar 4. Histogram tekstur dodol tepung buah mangrove pedada dengan menggunakan tepung buah mangrove dan tepung ketan yang berjumlah bervariasi.

Gambar 4 diatas menunjukan bahwa nilai organoleptik tekstur dodol buah mangrove berkisar 4,44 (agak suka) sampai 4,56 (suka). 
Nilai organoleptik tekstur tertinggi dan lebih baik yang diberikan penelis terdapat pada pemberian tepung mangrove sebanyak 20 gram dan tepung ketan sebanyak 180 gram (10\%) dibandingkan dengan kandungan tepung mangrove pedada 40 gram dan tepung ketan 160 gram (20\%), tepung mangrove 60 gram, tepung ketan 140 gram (30\%), tepung mangrove 80 gram, tepung ketan 120 gram (40\%), tepung mangrove 100 gram, tepung ketan 100 gram (50\%).

Hasil analisis ragam menunjukan bahwa jumlah variasi tepung mangrove dan tepung ketan memberikan pengaruh berbeda nyata terhadap tekstur dodol buah mangrove pedada.

Berdasarkan uji Beda Nyata Jujur (BNJ), menunjukan bahwa tekstur yang diberikan penelis terhadap dodol tepung buah mangrove pedada 20 gram dan tepung ketan 180 gram (10\%) tidak ada pengaruh perlakuan dengan jumlah tepung buah mangrove pedada 40 gram (20\%), 60 gram (30\%), 80 gram (40\%), dan 100 gram $(50 \%)$ dan tepung ketan 160 gram $(20 \%)$, 140 gram (30\%), 120 gram (40\%), dan 100 gram $(50 \%)$.

\section{Kesukaan Keseluruhan Dodol Buah Mangrove Pedada}

Menurut Oliver (dalam Supranto, 2001) mendefinisikan kepuasan sebagai tingkat perasaan seseorang setelah membandingkan suatu produk atau hasil yang dirasakannya dengan harapannya.

Data hasil pengamatan organoleptik kesukaan keseluruhan dodol buah mangrove pedada. Rataan nilai organoleptik kesukaan keseluruhan dodol buah mangrove pedada tertara pada Tabel 6.

\begin{tabular}{ccc} 
Subsitusi (\%) & Skor & NilaiBnj 5\% \\
10 & 4,2 & \\
20 & 4,04 & \\
30 & 4,92 & 0,71 \\
40 & 3,84 & \\
50 & 3,95 & \\
\hline
\end{tabular}

Rataan pengamatan organoleptik kesukaan keseluruhan dodol buah mangrove pedada dengan jumlah tepung buah mangrove pedada dan jumlah tepung beras (Rosebrand) yang bervariasi untuk lebih jelasnya juga disajikan pada Gambar 5.

Gambar 5 dibawah menunjukan bahwa nilai organoleptik kesukaan keseluruhan dodol buah mangrove berkisar 4 (agak suka) sampai 4,92 (suka). Nilai organoleptik kesukaan keseluruhantertinggi dan lebih baik yang diberikan penelis terdapat pada pemberian tepung mangrove sebanyak 20 gram dan tepung ketan sebanyak 150 gram (10\%) dibandingkan dengan kandungan tepung mangrove pedada 40 gram dan tepung ketan 160 gram (20\%), tepung mangrove 60 gram, tepung ketan 140 gram (30\%), tepung mangrove 80 gram, tepung ketan 120 gram (40\%), tepung mangrove 100 gram, tepung ketan 100 gram $(50 \%)$.

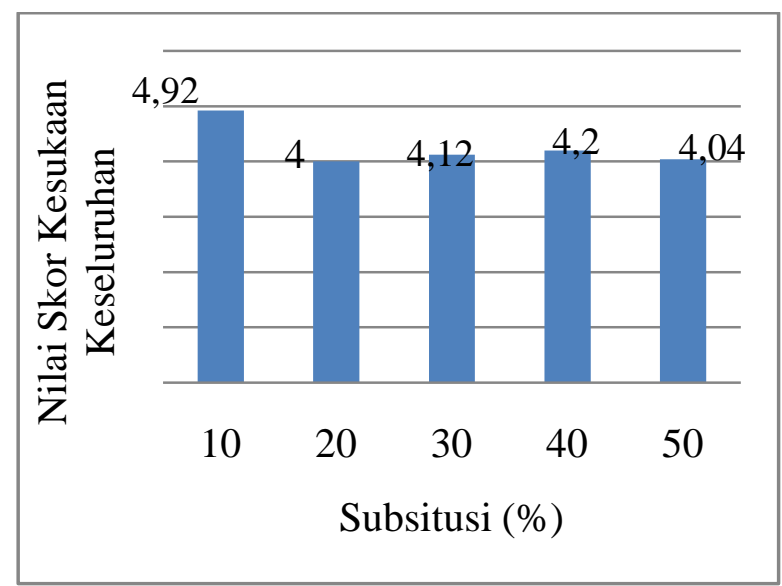

Gambar 5. Histogram kesukaan keseluruhan dodol tepung buah mangrove pedada dengan menggunakan tepung buah mangrove dan tepung ketan yang berjumlah bervariasi.

Hasil analisis ragam menunjukan bahwa jumlah variasi tepung mangrove dan tepung ketan memberikan pengaruh sangat nyata terhadap kesukaan keseluruhan dodol buah mangrove pedada.

Berdasarkan uji Beda Nyata Jujur (BNJ), menunjukan bahwa kesukaan keseluruhan yang diberikan penelis terhadap dodol tepung buah mangrove pedada 20 gram dan tepung ketan 180 gram $(10 \%)$ tidak ada pengaruh perlakuan dengan jumlah tepung buah mangrove pedada 40 gram (20\%), 60 gram (30\%), 80 gram (40\%), dan 100 gram $(50 \%)$ dan tepung ketan 160 gram (20\%), 140 gram (30\%), 120 gram (405), dan 100 gram $(50 \%)$.

Dari hasil keseluruhan uji organoleptik diatas yang dinilai oleh penelis dari tingkat kesukaan warna, aroma, rasa, tekstur, dan kesukaan keseluruhan menunjukan bahwa penelis lebih menyukai tingkat subsitusi $10 \%$ dengan menggunakan 20 gram tepung mangrove dan 180 gram tepung ketan.

\section{Pemasaran Dodol Buah Mangrove}

Menurut Stantondalam Abdul Majid (2008), pemasaran adalah sistem keseluruhan dari kegiatan usaha yang ditujukan untuk merencanakan, menentukan harga, 
mempromosikan dan mendistribusikan barang dan jasa yang dapat memuaskan kebutuhan pembeli maupun pembeli potensial.

Dari hasil penelitian pemasaran dodol buah mangrove yang dijalankan selama satu minggu dengan jumlah dodol sebanyak 200 bungkus dengan lokasi pemasaran yang berbeda-beda seperti lokasi kampus Politeknik Palu, Sekolah Dasar (SD) Negeri 4 Taipa Ginggiri, kalangan masyarakat Palupi dan Taipa ginggiri, dan pemasaran penitipan ke kios-kios yang ada dikota palu diantaranya kios Ramadhan Jl. Haji Hayun, kios Ruslan Jl. Ki Hajar, kios Fadilah Jl. Malino, dan kios Shri Jl. Moh. Hatta. Untuk lebih jelas dapat disajikan pada Tabel data hasil pengamatan penjualan dodol selama satu minggu pada Tabel 7.

Tabel 7 Data Pengamatan Penjualan Dodol buah Mangrove Pedada

\begin{tabular}{lllll}
\hline No & Pemasaran & Volume & $\begin{array}{c}\text { Harga } \\
\text { Satuan }\end{array}$ & Jumlah \\
\hline 1 & Kampus & 30 & Rp. & Rp. \\
& & Bungkus & 2.000 & 60.000 \\
2 & SD & 20 & Rp. & Rp. \\
& & Bungkus & 1.000 & 20.000 \\
3 & Masyarakat & 50 & Rp. & Rp \\
& & Bungkus & 2.000 & 100.000 \\
4 & Kios-kios & 100 & Rp. & Rp. \\
& & Bungkus & 1.800 & 180.000 \\
\hline & TOTAL & 200 & & Rp. \\
& & Bungkus & & $\mathbf{3 6 0 . 0 0 0}$ \\
\hline
\end{tabular}

Dari Tabel diatas dapat dilihat bahwa jumlah keseluruhan dodol yang terjual yaitu 200 bungkus dengan jumlah Rp. 360.000,00, jika dilihat dengan biaya tetap dan biaya tidak tetap yang berjumlah Rp. 108.000, maka usaha ini mendapatkan keuntungan dan usaha ini layak untuk dikembangkan lebih lanjut lagi, dan dari tabel diatas dapat dilihat dan menunjukan bahwa penjualan dodol buah mangrove dapat diterima oleh para konsumen.

\section{Kesimpulan dan Saran}

\section{Kesimpulan}

Berdasarkan hasil penelitian maka disimpulkan bahwa hasil uji organoleptik dan hasil pemasaran dodol buah mangrove pedada adalah :

1. Dari hasil penelitian ini didapat nilai organolptik tertinggi terhadap warna, aroma, rasa, tekstur dan kesukaan keseluruhan dodol buah mangrove dengan subsitusi $10 \%$ dimana tepung mangrove 20 gram dan tepung ketan 180.
2. Dari hasil pemasaran dodol buah mangrove yang berjumlah Rp. 360.000 , bila dibandingkan dengan biaya variabel dan biaya tetap sebanyak Rp. 108.000 maka usaha dodol ini layak untuk dijalankan, karena selain mendapatkan keuntungan, dodol buah mangrove juga dapat diterima oleh konsumen.

\section{Saran}

Perlu diadakan pengujian kandungan gizi agar lebih diketahui manfaat kesehatan bila dikonsumsi. Adanya survei dalam pemasaran, agar dapat diketahui berapa banyak yang suka dengan dodol dari tepung buah mangrove dan yang tidak suka dodol dari tepung buah mangrove.

\section{Daftar Pustaka}

Abdul, majid. 2008. Pengertian Konsep Defenisi pemasaran. Pontianak

Bengen, D., 2002. Sinopsis Ekosistem dan Sumber Daya Alam Pesisir dan laut. Pusat Kajian Sumber Daya Pesisir dan lautan IPB, Bogor

Dahuri, R., J. Rais, S.P. Ginting Dan M.J. Sitepu, 2001. Pengolahan Sumberdaya Wilaya Pesisir dan Lautan Secara terpadu. P.T. Pradnya Pramita, Jakarta

Hardiman, 1991. Kumpulan Handout: Tekstur Pangan. PAU Pangan dan Gizi $U G M$,Jogjakarta

Hudaya Rn. 2008. Pemanfaatan Buah Pedada Senoratia Caseolaris. https://lidiabayang.wordpress.com/2010/06 /17/pemanfaatan-buah-pedada-sonneratiacaseolaris. Diakses 04 agustus 2015

Meilgaard, M., Civille G.V., Carr B.T. 2000. Sensory Evaluation Techniques.Boca Raton, Florida: CRC Press.

Moehyi, S., 1992. Penyelenggara Makanan dan Jasa Boga. Bharata. Jakarta.

Soekarto, S.T. 2002. Penilaian Organoleptik untuk Industri Pangan dan Hasil Pertanian. Bhratara Karya Akasara. Jakarta

Supranto, 2001. pengertian-kepuasan-konsumen. http://pujihpoltekkes.wordpress.com/2010/ 12/10/kepuasan/ Diakses 04 agustus 2015

Winarno, F.G. 2002. Kimia Pangan dan Gizi. Penerbit PT Gramedia Pustaka Utama. Jakarta. 